\title{
Effect of IFN-A on immune responses and plasmacytoid dendritic cell functions of patients with hepatitis $B$.
}

\author{
Yue Chen" ${ }^{1}$, Jiaen Yang ${ }^{1}$, Jingmo Tang ${ }^{1}$, Qianguo Mao' ${ }^{1}$, Qizhong Zheng ${ }^{2}$, Ying Zheng ${ }^{*}$ \\ ${ }^{1}$ Hepatology Unit, Xiamen Hospital of Traditional Chinese Medicine, Beijing University of Traditional Chinese \\ Medicine, Xiame, PR China \\ ${ }^{2}$ Pathology Department, Xiamen Hospital of Traditional Chinese Medicine, Beijing University of Traditional Chinese \\ Medicine, Xiame, PR China
}

\begin{abstract}
Objective: To explore the impact of IFN- $\alpha$ on immune response of patients with hepatitis $B$ and the functions of plasmacytoid Dendritic Cells (pDCs).

Methods: A total of 96 patients with hepatitis $B$ were involved in the study and randomly assigned into control group and experimental group, 48 a group. Both groups underwent usual treatment, besides, the experimental group was given IFN- $\alpha$. After treatment, all patients were tested for serum AST, ALT and IFN- $\alpha$, as well as peripheral $\mathrm{CD4}^{+}, \mathrm{CD8}^{+}, \mathrm{CD4}^{+} / \mathrm{CD8}^{+}$, and $\mathrm{pDCs}$.

Results: Compared with the control group, the peripheral $\mathrm{CD4}^{+}$and $\mathrm{CD4}^{+} / \mathrm{CD8}^{+}$of the experimental group after treatment were much more than those of the control group. Serum IFN- $\alpha$ and peripheral pDCs of the experimental group were also more than that of the control group $(P<0.05)$; while serum AST and ALT of the experimental group were much less than that of the control group $(P<0.05)$.

Conclusion: IFN- $\alpha$ is able to greatly enhance the immune responses of patients with hepatitis $B$ and functions of plasmacytoid dendritic cells, improving liver function.
\end{abstract}

Keywords: Immune responses, Plasmacytoid dendritic cell, Hepatitis B.

Accepted on December 27, 2017

\section{Introduction}

Hepatitis B Virus (HBV) infection is a global healthy issue, and approximate 2 billion people worldwide have been infected with HBV, of which 350-400 million are chronic HBV infection, and about 1 million persons die of HBV infectioninduced liver failure, liver cirrhosis and primary hepatocellular carcinoma every year [1]. Hepatitis B is an infectious disease caused by HBV, with liver inflammatory lesions, which can give rise to multi-organs damage [2]. As a high incidence area of hepatitis B, China has more than 20 million patients with Chronic Hepatitis B (CHB) at present, and hepatitis B-related diseases result in 237, 000 deaths every year, of which 156, 000 die of liver cancer [3], with an uptrend in incidence year by year. CHB has strong infectivity and gets a relapse easily which develops into liver cirrhosis or even liver cancer, badly threatening patients' lives. Therefore, a proper and effective treatment is essential for CHB patients at early stage. It is internationally recognized that IFN- $\alpha$ and nucleoside analogues are the main drugs for the anti-virus therapy of chronic hepatitis B. IFN- $\alpha$ is the sole drug approved for the anti-virus therapy of hepatitis $\mathrm{B}$ and immunoregulation that can stimulates the body to produce immune responses with $\mathrm{HBV}$ specificity. Compared with nucleoside analogues, IFN- $\alpha$ cannot lead to drug-fast virus and has a relatively definite treatment course. Consequently, the study observes the changes of Alanine Transaminase (ALT), Aspartate Aminotransferase (AST), and IFN- $\alpha$ in serum and $\mathrm{CD}^{+} \mathrm{T}$ helper cells $\left(\mathrm{CD}^{+}\right)$, $\mathrm{CD}^{+} \mathrm{T}$ helper cells $\left(\mathrm{CD} 4^{+}\right), \mathrm{CD}^{+} / \mathrm{CD}^{+}$, and plasmacytoid Dendritic Cells (pDCs) in peripheral blood of patients before and after treatment to investigate the effect of IFN- $\alpha$ on the immune response of patients with hepatitis B and functions of pDCs.

\section{Data and Methods}

\section{Clinical data}

A total of 96 patients with $\mathrm{CHB}$ diagnosed in infection department from December 2015 to December 2016 were enrolled in the study and divided randomly into control group and experimental group, 48 a group. In the experimental group, there were 25 males, 23 females, aged from 22 to $70 \mathrm{y}$, (41.6 \pm $11.5 \mathrm{y})$ in average, with a mean course of $(9.1 \pm 3.8$ months $)$. And in the control group, there were 24 males, 24 females, aged from 24 to $68 \mathrm{y},(39.8 \pm 12.3 \mathrm{y})$ in average, with a mean course of $(9.5 \pm 4.2$ months $)$. Compared two groups, there was no statistical difference in general clinical data like sex, age, and mean course of disease. The study had been approved by ethnic committee and all participants signed an informed 
consent. All patients were diagnosed in the light of the diagnosis standards of CHB in Guidelines for Preventing and Treating of Chronic Hepatitis B (2010) drafted by Chinese Society of Hepatology in 2010 [4] and experimental outcomes. If patients had negative $\mathrm{HbeAg}$ and other chronic liver diseases, hepatitis $\mathrm{C}$ and $\mathrm{D}$, autoimmune liver disease, heart failure, renal dysfunction, and malignant tumors, and if patients took anti-viral drugs recently, and if patients were allergic to the drugs used in the study, they all were ineligible to the study.

\section{Methods}

Treatment methods: According to the guidelines for clinical medication, all patients were given usual liver protectants and symptomatic treatments for one year. In addition, the patients in the experimental group were injected IFN- $\alpha$ intramuscularly, $500-600 \times 10^{4} \mathrm{IU}$ each time, with a treatment course of $48 \mathrm{w}$, once a week until the end.

Collection of serum indexes: All patients on an empty stomach for $12 \mathrm{~h}$ at least were collected $5 \mathrm{ml}$ venous blood before and after treatment that were centrifuged for serums of which ALT and AST were tested by performance rate method. And IFN- $\alpha$ in serum was determined with a full functional ELISA provided by BioTek Synergy, American, of which operations were strictly in the light of the introductions of IFN$\alpha$ assay kit.
Cytology assay: $3 \mathrm{ml}$ fasting venous blood drawn from each patient before and after treatment were put into an anticoagulation tube and detected for peripheral $\mathrm{CD} 4^{+}, \mathrm{CD} 8^{+}$, $\mathrm{CD}^{+} / \mathrm{CD}^{+}$, and $\mathrm{pDCs}$ with Gallios flow cytometry from Beckman Coulter, Inc.

\section{Statistical analysis}

All data were analysed by software SPSS20.0. The outcomes were expressed by mean $\pm \mathrm{SD}$, and t-test was used for the comparison between groups, while one-way ANOVA for the comparison within groups. When $\mathrm{P}$ was less than 0.05 , the difference was statistically significant.

\section{Results}

\section{Comparison on peripheral $\mathrm{CD}^{+}, \mathrm{CDB}^{+}$and $\mathrm{CD4}^{+} / \mathrm{CDB}^{+}$of two groups before and after treatment}

After treatment, peripheral $\mathrm{CD} 4^{+}, \mathrm{CD}^{+}$and $\mathrm{CD} 4^{+} / \mathrm{CD}^{+}$of two groups were greatly increased, and the increases of $\mathrm{CD} 4^{+}$ and $\mathrm{CD} 4^{+} / \mathrm{CD}^{+}$in the experimental group was much more than those in the control group $(\mathrm{P}<0.05)$; while compare two groups, there was no statistical difference in $\mathrm{CD}^{+}$after treatment $(\mathrm{P}<0.05$, Table 1$)$.

Table 1. Comparison on peripheral $\mathrm{CD}^{+}, \mathrm{CD} 8^{+}$and $\mathrm{CD} 4^{+} / C D 8^{+}$of two groups before and after treatment.

\begin{tabular}{llllc}
\hline Group & $\mathbf{n}$ & Time & CD4 $^{+}$(\%) & CD8 $^{+}$(\%) \\
\hline Control group & 48 & Before treatment & $31.81 \pm 3.84$ & $28.37 \pm 3.31$ \\
\cline { 3 - 5 } & & After treatment & $34.13 \pm 4.21^{*}$ & $27.67 \pm 3.51$ \\
\hline Experimental group & 48 & Before treatment & $31.43 \pm 4.11$ & $28.27 \pm 3.51$ \\
\cline { 2 - 5 } & & After treatment & $45.13 \pm 5.13^{*}$ & $27.91 \pm 3.79$ \\
\hline
\end{tabular}

${ }^{*} \mathrm{P}<0.05$, compared with the same group before treatment, ${ }^{\#} \mathrm{P}<0.05$, compared with the control group after treatment.

\section{Comparison on serum IFN- $\alpha$ and peripheral pDCs of two groups before and after treatment}

After treatment, the serum IFN- $\alpha$ and peripheral pDCs of two groups went up largely; and compared two groups, the serum IFN- $\alpha$ and peripheral pDCs of the experimental group raised more than that of the control group $(\mathrm{P}<0.05$, Table 2$)$.

Table 2. Comparison on serum IFN- $\alpha$ and peripheral pDCs of two groups before and after treatment.

\begin{tabular}{lllll}
\hline Group & $\mathbf{n}$ & Time & IFN- $\alpha(\mathbf{n g} / \mathbf{L})$ & pDCs (\%) \\
\hline Control group & \multirow{2}{*}{48} & Before treatment & $3.15 \pm 0.51$ & $0.25 \pm 0.02$ \\
\cline { 3 - 5 } & & After treatment & $3.81 \pm 0.32^{*}$ & $0.28 \pm 0.03^{*}$ \\
\hline Experimental group & 48 & Before treatment & $3.23 \pm 0.41$ & $0.24 \pm 0.03$ \\
\cline { 2 - 4 } & & After treatment & $6.21 \pm 0.56^{* \#}$ & $0.45 \pm 0.04^{*}$ \\
\hline
\end{tabular}

${ }^{*} \mathrm{P}<0.05$, compared with the same group before treatment, ${ }^{\#} \mathrm{P}<0.05$, compared with the control group after treatment.

\section{Comparison on serum AST and ALT of two groups before and after treatment}

After treatment, serum AST and ALT of two groups largely raised; and serum AST and ALT of the experimental group was much less than that of the control group $(\mathrm{P}<0.05$, Table 3$)$.

Table 3. Comparison on serum AST and ALT of two groups before and after treatment.

\begin{tabular}{lllll}
\hline Group & $\mathbf{n}$ & Time & AST & ALT \\
\hline Control group & \multirow{2}{*}{48} & Before treatment & $98.32 \pm 13.15$ & $148.11 \pm 23.12$ \\
\cline { 2 - 4 } & & After treatment & $73.57 \pm 9.13^{*}$ & $98 \pm 9.61^{*}$ \\
\hline
\end{tabular}




\begin{tabular}{llll}
\hline $\begin{array}{l}\text { Experimental } \\
\text { group }\end{array} 48$ & Before treatment & $99.21 \pm 14.76$ & $148.57 \pm 22.22$ \\
\cline { 2 - 3 } & After treatment & $28.57 \pm 6.59^{* \#}$ & $38.24 \pm 8.61^{* \#}$ \\
\hline
\end{tabular}

${ }^{*} \mathrm{P}<0.05$, compared with the same group before treatment, ${ }^{\#} \mathrm{P}<0.05$, compared with the control group after treatment.

\section{Discussion}

China is a moderate prevalent area of HBV infection, with a HBsAg prevalence rate of $7.18 \%$ in group aged from 1 to $59 \mathrm{y}$ $[5,6]$, and there are about 93 million chronic HBV carriers, of which 20 million are CHB patients [7]. The incidence of liver cirrhosis in the untreated CHB patients is approximate $2.1 \%$, and among the patients infected HBV before six years old, about $25 \%$ will suffer from liver cirrhosis or HCC [4]. The annual incidence of decompensated cirrhosis induced by $\mathrm{HBV}$ or $\mathrm{CHB}$ is about $3 \%$, and the cumulative incidence of $5 \mathrm{y}$ is about $16 \%$, and the $5 \mathrm{y}$ case fatality rate of $\mathrm{CHB}$, compensated or decompensated cirrhosis is $0 \%-2 \%, 14 \%-20 \%$, and $70 \%-86 \%$, respectively [4].

In recent years, with the increasing spread of $\mathrm{HBV}$ vaccination in China, the occurrence of $\mathrm{CHB}$ has been under control, but its morbidity and mortality are still on the rise, resulting in great suffering to patients and their families. The main manifestations of $\mathrm{CHB}$ in clinic include poor appetite, fatigue, abdominal bloating, nausea, hepatalgia and so forth [8], and the severe cases may have hepatosplenomegaly, jaundice, hepatalgia, fatty liver, liver cirrhosis, liver cancer and other serious complications, endangering the patients' lives. It is internationally recognized that IFN- $\alpha$ and nucleoside analogues are the main drugs for the anti-virus therapy of chronic hepatitis B. And IFN- $\alpha$ is the only drug approved for the antivirus therapy of hepatitis $\mathrm{B}$ and immunoregulation that can stimulates the body to produce immune responses with $\mathrm{HBV}$ specificity. Compared with nucleoside analogues, IFN- $\alpha$ cannot lead to drug-fast virus and has a relatively definite treatment course.

Accordingly, in the trial, we observe the changes of immune responses and pDCs functions in the patients before and after treatment and explore the effect of IFN- $\alpha$ on chronic hepatitis $\mathrm{B}$ patients and its mechanisms. The findings of the study reveal that peripheral $\mathrm{CD}^{+}$and $\mathrm{CD}^{+} / \mathrm{CD}^{+}$of the patients in both groups after treatment are much more than that before treatment $(\mathrm{P}<0.05)$. The increases of peripheral $\mathrm{CD}^{+}$and $\mathrm{CD}^{+} / \mathrm{CD}^{+}$in the experimental group are more than that in the control group $(\mathrm{P}<0.05)$; compared before and after treatment, there is no difference in peripheral $\mathrm{CD}^{+}$of two groups $(\mathrm{P}>0.05)$. IFN- $\alpha$ is able to enhance patients' immune function. And T lymphocytes are a vital part of immune system that can reflect body immune condition. In CHB patients, $\mathrm{CD}^{+}$can promote $\mathrm{B}$ lymphocytes to produce antibodies, so as to clear away HBV [9,10]. Through inducing cells to synthetize anti-virus protein and restraining the duplication of HBV, IFN- $\alpha$ has a broad-spectrum antivirus effect. As a kind of natural antigen presenting cells, pDCscan synthetize and release a massive of IFN- $\alpha$. A study demonstrates that the amount and functions of $\mathrm{pDCs}$ in $\mathrm{CHB}$ patients decline
$[11,12]$. The outcomes of the study indicate that after treatment, the serum IFN- $\alpha$ and peripheral pDCs of two groups go up largely; and compared two groups, the serum IFN- $\alpha$ and peripheral $\mathrm{pDCs}$ of the experimental group are more than those of the control group $(\mathrm{P}<0.05)$. IFN- $\alpha$ is able to improve the function of $\mathrm{pDCs}$ and rebuild the anti-virus effect of body. Therefore, serum AST and ALT levels of the patients in two groups after treatment are much higher than those before treatment; and that of the experimental group are much less than that of the control group $(\mathrm{P}<0.05)$, showing that the patients' liver function is regained.

In conclusion, we analyse the changes of serum AST, ALT, and IFN- $\alpha$, and peripheral $\mathrm{CD} 4^{+}, \mathrm{CD} 8^{+}, \mathrm{CD} 4^{+} / \mathrm{CD}^{+}$, and $\mathrm{pDCs}$ of $96 \mathrm{CHB}$ patients and confirm that IFN- $\alpha$ can largely enhance the immune responses and pDCs function of $\mathrm{CHB}$ patients and improve liver function, which provide some guides for clinical treatment and references for further studies on molecular mechanism.

\section{Acknowledgements}

Xiamen science and technology fund/Research on $\mathrm{pDC}$ quantity and function in hepatic tissue of $\mathrm{HBeAg}$ positive chronic hepatitis B patient/3502Z20144028.

\section{References}

1. Jule SL, Dienstag MD. Hepatitis B of virus infection. N Eng J Med 2008; 359: 1486-1500.

2. Li M, Chen LF, Zhao YQ. Advances in treating chronic hepatitis B with supplementing qi and removing toxin. J Hubei Univ Chin Med 2013; 15: 72-74.

3. Zhang M. Clinical analysis on 48 cases of chronic hepatitis B patients. Chin J Clin Rati Drug Use 2012; 5: 39.

4. Chinese Society of Hepatology, Society of infectious diseases, CMA. Guidelines for Preventing and Treating of Chronic Hepatitis B, 2010. Chin Prev Med 2011; 12: 1-15.

5. Liang X, Bi S, Yang W. Epidemiological serosurvey of hepatitis $\mathrm{B}$ in China-declining HBV prevalence due to hepatitis B vaccination. Vaccine 2009; 27: 6550-6557.

6. Liang X, Bi S, Yang W. Evalution of the impact of hepatitis B vaccination among children born during 1992-2005 in China. J Infect Dis 2009; 200: 39-47.

7. Lu FM, Zhuang H. Management of hepatitis B in China. Chin Med J (Engl) 2009; 122: 3-4.

8. Gao J, Wang GP, Zhao CY. Clinical observation on changes of serum IL-10, IL-12, sIL-2R, and TNF in chronic hepatitis $\mathrm{B}$ patients underwent anti-viral therapy. Heibei Med J 2013; 35: 2132-2133.

9. Chen Y, Chen HT, Wu SP. Effects of adefovir dipivoxil on peripheral blood dendritic cells and lymphocyte subsets in patients with chronic hepatitis B. Guangdong Med J 2010; 31: 72-74.

10. Xiao Y. Changes of peripheral blood T lymphocyte subsets and IL-2 in patients with chronic hepatitis B receiving Bupleurum Jiedu decoction combined with adefovir dipivoxil therapy. J Pract Hepatol 2017. 
11. Tang YY, Li D, Yu YS. Advances on pDCs in chronic hepatitis B. Chin J Clin Pharm Ther 2012; 17: 1062-1066.

12. Jia N, Lin L, Guo S. Clinical profiles of circulating plasmacytoid dendritic cells in chronic hepatitis B patients in response to pegylated-interferon alfa-2a treatment. Zhonghua Gan Zang Bing Za Zhi 2015; 23: 34-39.

\section{*Correspondence to}

Zheng Ying

Hepatology Unit

Xiamen Hospital of Traditional Chinese Medicine

Beijing University of Traditional Chinese Medicine

PR China 